\title{
Dakin's solution: is there a place for it in the 21st century?
}

\author{
Bruno Duarte ${ }^{1}$, Joana Cabete ${ }^{1}$, Ana Formiga ${ }^{2} \&$ José Neves $^{2}$ \\ 1 Dermatology Department, Hospital de Santo António dos Capuchos - Centro Hospitalar de Lisboa Central, Lisbon, Portugal \\ 2 General Surgery Department, Hospital de Curry Cabral - Centro Hospitalar de Lisboa Central, Lisbon, Portugal
}

\author{
Key words \\ Dakin's solution; Diabetic foot; Wound \\ healing

\section{Correspondence to} \\ Bruno Duarte \\ Department of Dermatology \\ Hospital de Santo António dos \\ Capuchos - Centro Hospitalar de Lisboa \\ Central \\ Alameda Santo António dos Capuchos \\ 1169-050 Lisbon \\ Portugal \\ E-mail: brunoduarte@campus.ul.pt
}

doi: 10.1111/iwj.12728
Duarte B, Cabete J, Formiga A, Neves J. Dakin's solution: is there a place for it in the 21st century?. Int Wound J 2017; 14:918-920

\section{Abstract}

Dakin's solution (DS) is a time-honoured antiseptic that still remains part of the wound care armamentarium. In spite of its cytotoxicity, some question its use in the current era. We report the case of a 52-year-old diabetic woman who was admitted for sepsis because of a severely infected diabetic foot. Urgent surgical drainage and debridement left a $9 \times 9$-cm deep, complex, infected wound with both bone and tendon involvement. Treatment with local negative pressure was unsuccessful. DS was regularly instilled through a tube left in the wound dressing. A marked improvement was observed with this strategy as the wound bed was much cleaner and fully granulated after 6 weeks. No adverse effects were noted. This case debunks the myth that topical antiseptics necessarily impair wound healing. DS can still be considered an option for difficult-to-treat, complex and heavily infected wounds.

\section{Introduction}

Dakin's solution (DS) received its name as homage to its creator, Henry Dakin. It was first introduced during the World War I pre-antibiotic era to meet the need of effective treatments for infected war wounds. Countless limbs and lives were saved because of this solution (1). The last few decades have seen a multitude of medical advancements, which have made a new array of antiseptic medical solutions available to medical practitioners. Nevertheless, Henry Dakin's formula is still occasionally used in current practice. However, some question if DS still has any role to play in the current era.

\section{Case report}

A 52-year-old woman presented to the emergency department complaining of a painful discolouration in the left foot with a 1-week evolution. Her history was remarkable for essential arterial hypertension and for type 1 diabetes mellitus, known for 16 years, with insufficient metabolic control and related complications: retinopathy, stage III chronic kidney disease and diabetic foot. The latter had led to the amputation of the right first toe and second left toe in 2007 and 2012, respectively.

On physical examination, the patient had wet gangrene of the first toe and an extensive necrotic plaque on the medial border and plantar surface of the left foot (Figure 1A and B), with marked perilesional inflammatory signs. Both dorsal and medial plantar foot compartments were under tension.
Additionally, she had a fever $\left(38 \cdot 1^{\circ} \mathrm{C}\right)$, nausea and vomiting. However, she was haemodynamically stable and had no respiratory distress.

Analytically, the patient had normocytic normochromic anaemia (haemoglobin $6.6 \times 10 \mathrm{~g} / \mathrm{l}$ ), raised inflammatory markers $\left(19.3 \times 10^{9} / 1\right.$ leucocytes, of which $92 \%$ were neutrophils, and a C-reactive protein of $284.6 \mathrm{mg} / \mathrm{l}$ ), and acute kidney injury (creatinine $2.28 \mathrm{mg} / \mathrm{dl}$ and urea $159 \mathrm{mg} / \mathrm{dl}$ ). The $\mathrm{X}$-ray of the left foot (Figure 1C) showed multiple gas bubbles on the subcutaneous tissue and periosteal erosions on the first metatarsal bone, suggesting osteomyelitis.

A diagnosis of diabetic foot with severe infection and sepsis was made (perfusion, extent, depth, infection and sensation: PEDIS classification system, grade IV), and she was hospitalised under the care of a specialised diabetic foot team.

Urgent surgical drainage and extensive debridement thus ensued (Figure 2A), leaving the patient with a $9 \times 9-\mathrm{cm}$ deep and complex infected wound with dorsal and plantar aponeurosis involvement, exposition of the first metatarsal bone and

\section{Key Messages}

- there is some concern that topical antiseptics might impair wound healing, and some entities strongly discourage their use

- our experience demonstrates that they can be beneficial if used correctly and in proper time of infection 
Figure 1 (A) Dorsal view of the left foot at presentation. (B) Medial view. (C) Dorsal-plantar and oblique $\mathrm{X}$-rays showing multiple gas bubbles on the subcutaneous tissue (white arrows).
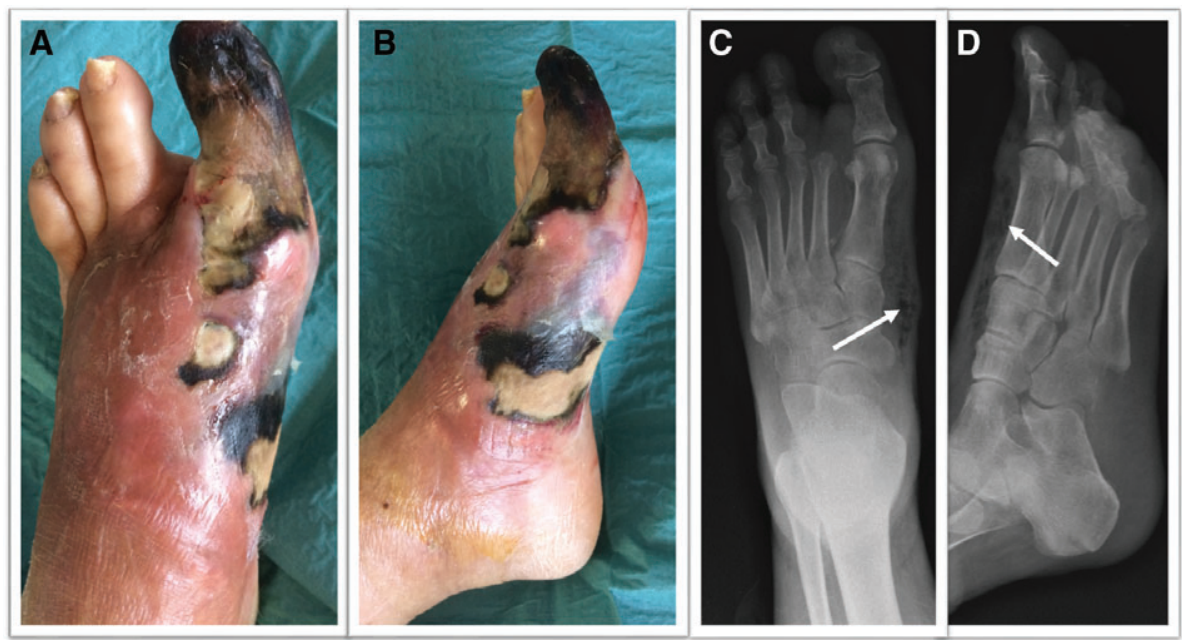
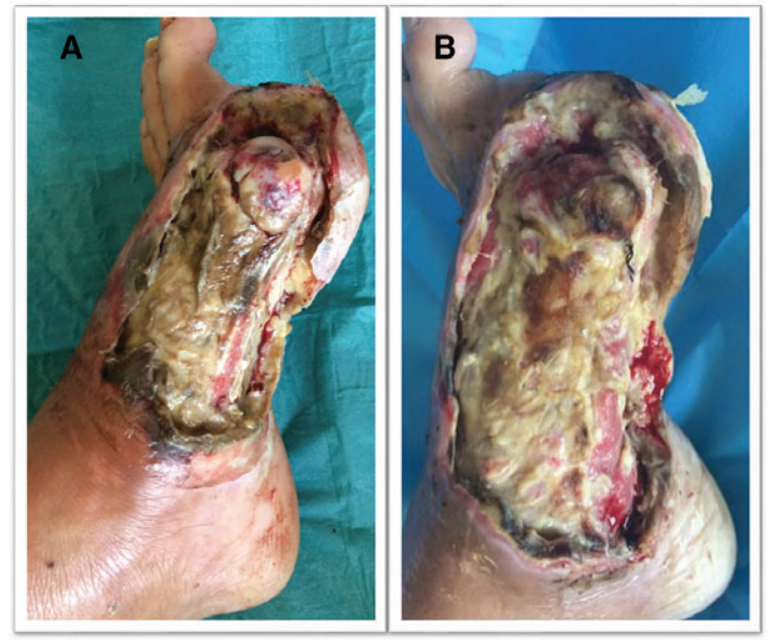

Figure 2 (A) Twenty-four hours after surgical drainage and debridement. (B) One week after surgical and local negative pressure treatment.

both extensor and flexor tendons of the first finger. Samples for microbiological study were collected, and an empirical treatment with broad-spectrum antibiotics was initiated. Dressings were done with thin gauzes soaked in octenidine solution. A Doppler ultrasound excluded peripheral arterial disease.

During hospitalisation, the medical team changed the dressings every other day, and wound cleansing and debridement were performed with Jetox ${ }^{\circledR}$-ND DeRoyal ${ }^{\circledR}$ using a mixture of 100-cc saline solution with 40-cc octenidine. Local negative pressure (LNP) was trialled during the first week, but this strategy met no success (Figure 2B). Following this attempt, DS was used by lightly packing gauzes moist with the solution into the wound and covering it with a secondary dressing. An irrigation tube was left wrapped in the dressing so that $50 \mathrm{cc}$ of DS could be instilled every 8 hours to maintain a humid environment.

With the aforementioned local care, antibiotic therapy, offloading of the foot and treatment of comorbidities, excellent and steady improvement was observed during 6 weeks of hospitalisation (Figure $3 \mathrm{~A}-\mathrm{C}$ ). The wound was then much cleaner and completely covered with granulation tissue. The patient had no complains related to the application of DS, and no contact dermatitis or other side effects were observed.

\section{Discussion}

Diluted sodium hypochlorite, widely known in the medical community as DS, is a time-honoured topical antiseptic that was introduced to the wound care armamentarium almost a century ago (1).

Nowadays, as McCullough et al. noted (2), advanced wound care knowledge has shifted the paradigm from 'prevention of infection' to 'creation of an optimal environment for the repair process'. For some, this raised concerns that antiseptics might be too cytotoxic for the healing process to occur. Some entities have even published guidelines that strongly discourage the use of antiseptics, particularly DS, for wound care (3). In our perspective, however, wound management is complex and not as straightforward as each agent has its own advantages as long as it is used correctly and tailored to each individual's situation.

Firstly, severely infected wounds clearly benefit from an aggressive approach in the beginning stages, the so-called inflammatory phase (1), when the pathogen burden is so high that any healing process is next to impossible (4). The goal of this phase is to rapidly decrease the bioburden and debride the inviable tissues in order to stop the destructive process and the spread of infection. As long as it is correctly used (as described below), DS is very useful because of its good antimicrobial and debridement properties (5-8). After quickly achieving infection control, the focus can shift to stimulate granulation.

The case we present debunks the myth that antiseptics could impair the healing process because of their cytotoxic properties. The wound bed was totally covered with granulation tissue after 6 weeks in spite of being irrigated with $50 \mathrm{cc}$ of DS every 8 hours (Figure $3 \mathrm{C}$ ). It should be noted that this periodic flooding contributed to maintaining a moist environment in the wound, which is optimal to promote granulation (9). Of course, if the wound is totally clean, the bath can be stopped as DS, much like other antiseptics, is not a cicatrising agent.

Ulcers are devoid of an epidermal barrier and physiological skin defences (immune cells, natural skin antimicrobial peptides), thus compromising the local bacterial equilibrium and 

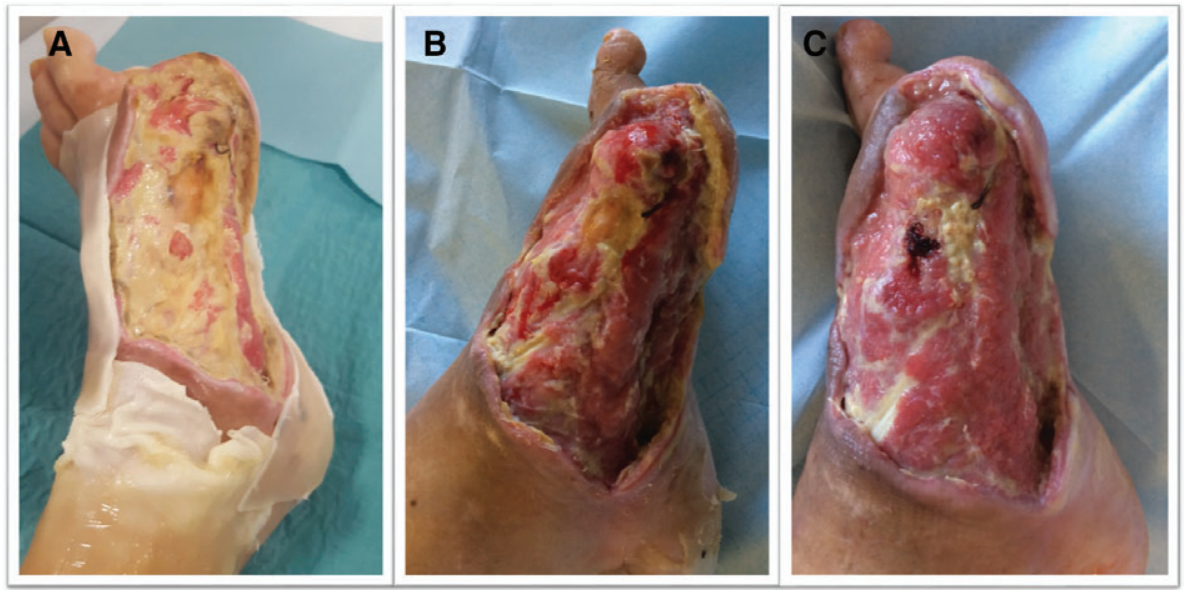

Figure 3 (A) One week of irrigation with Dakin's solution; hydrocolloid dressing protecting the perilesional skin. (B) Four weeks of irrigation. (C) Complete granulation of wound bed is observed after 6 weeks of irrigation with Dakin's solution.

favouring infection, especially in patients whose immune function is defective, such as diabetics with poor metabolic control. High-risk wounds with a heavy load of inviable, infected tissues, such as in the case we present, might locally benefit from the use of antiseptics such as DS. Proper usage of DS in wound care is, however, mandatory to obtain good results. Its antimicrobial and debridement proprieties are short lived (6-8 hours), so applying it only once a day is almost the same as using a dry dressing, which is utterly inefficient. In our practice, we leave a tube (butterfly) in the dressing for cyclical instillation into the wound. Another option would be to undertake frequent dressing changes (three to four times a day), but this is more timeand resource-consuming.

The case we present is of a diabetic foot with a polimicrobial infection and anaerobic involvement, as suggested by the bubbles of gas seen on the foot's X-ray (Figure 1C). Unlike other antiseptics, DS is efficacious against both aerobic and anaerobic bacteria (5). It is also known that the prevalence of multidrug-resistant organisms (MDROs) on diabetic foot ulcer inpatients is high, as observed in a 2011 study performed at our unit (10). DS has superior activity against MDROs when compared with other antiseptics (11), which further validates our treatment strategy.

Perilesional skin irritant contact dermatitis is often a concern (3). In order to prevent this, we use a hydrocolloid dressing to protect the wound's borders (Figure 3A). With this procedure, no irritation is routinely observed.

Lastly, it should be mentioned that the most cited evidence against DS (3) is from cell cultures and bench investigation. Recreating how an infected human wound behaves in the laboratory is not an easy task, and the clinical relevance of those studies should be cautiously interpreted by experienced wound care practitioners (8).

\section{Conclusion}

Discouraging the use of an agent with such empirical and observational experience accumulated over the years should not be performed lightly. In our experience, DS is an effective agent when used correctly and in proper time of infection. It is also our experience that it does not impair wound-healing potential. DS should be considered for difficult-to-treat, complex and heavily infected wounds.

\section{References}

1. Levine J. Dakin's solution: past, present and future. Adv Skin Wound Care 2013;26:410-4.

2. McCullough M, Carlson GW. Dakin's solution historical perspective and current practice. Ann Plast Surg 2014;73:254-6.

3. Utilização de Hipoclorito de Sódio $0.5 \%$ (Soluto Dakin) na limpeza de feridas. Ordem dos Enfermeiros, Parecer No. 152/2009

4. Xu L, McLenna SV. Bacterial load predicts healing rate in neuropathic diabetic foot ulcers. Diabetes Care 2007;30:378-80.

5. Altunoluk B, Resim S, Efe E, Eran E, Altunoluk M, Benlioglu C, Kankilic N, Baykan H. Fournier's gangrene: conventional dressings versus dressings with Dakin's solution. ISRN Urol 2012; 2012:762340.

6. Cornwell P, Arnold-Long M, Barss SB, Varnado MF. The use of Dakin's solution in chronic wounds: a clinical perspective case series. J. Wound Ostomy Continence Nurs 2010;37:94-104.

7. Raffernsperger J. Debridement of wounds with Dakin's solution. Arch Surg 1989;124:133.

8. Lewandowski L, Lewandowski L, Purcell R, Fleming M, Gordon WT. The use of dilute Dakin's solution for the treatment of angioinvasive fungal infection in the combat wounded: a case series. Mil Med 2013;178: $503-7$.

9. Junker JP, Kamel RA, Caterson EJ, Eriksson E. Clinical impact upon wound healing and inflammation in moist, wet, and dry environments. Adv Wound Care 2013;2:348-56.

10. Cabete J, Moniz L, Pinto M, Neves J, Pereira AC. Caracterização do perfil microbiológico e de sensibilidade antimicrobiana dos microrganismos isolados em úlceras diabéticas de um hospital português. Rev Por Cir CardioToracica e Vascular 2011;18: 53-60.

11. Neely AN, Gardner J, Durkee P, Warden GD, Greenhalgh DG, Gallagher JJ, Herndon DN, Tompkins RG, Kagan RJ. Are topical antimicrobials effective against bacteria that are highly resistant to systemic antibiotics? J Burn Care Res 2009; 30:19-29. 